\title{
Advanced Treatment Technology for Wastewater from Snakehead Fish Culturing Tank
}

\author{
Pham Van Toan ${ }^{1}$, Mai Phuoc Vinh ${ }^{1}$, Nguyen Van Dung ${ }^{2}$, and Jiro Koyama ${ }^{3}$ \\ ${ }^{1}$ College of Environment and Natural Resources, Can Tho University, Vietnam \\ ${ }^{2}$ College of Engineering Technology, Can Tho University, Vietnam \\ ${ }^{3}$ Kagoshima University, Japan
}

\begin{abstract}
In the recent years, culture of snakehead fish in the lined tanks has been rather rapidly developed in the Vietnamese Mekong Delta. According to previous researches, more than 23\% of households culturing snakehead fish in lined tanks and 90\% interviewed households did not treat wastewater before discharging into receiving water bodies. In this study, treatment of wastewater from the lined tank of snakehead fish was performed by combining the coagulation-flocculation, sedimentation and cold plasma technologies. Wastewater was treated at lab-scale condition. Study results showed that the effluent treatment efficiency on the model reached over 70\% for BOD, COD, phosphorus and total coliforms. Quality of wastewater after treatment met the Vietnamese national regulation for industrial wastewater quality (QCVN 40:2011/BTNMT). However, electrical conductivity of water after treatment increased and the treatment efficiency of cold plasma was not high; it is necessary to be improved in further researches.
\end{abstract}

Keywords: Snakehead fish culture, lined tank, wastewater, coagulation-flocculation, cold plasma

\section{Introduction}

Snakehead fish (Channa Striata) is a freshwater fish that is widely cultivated in the Vietnamese Mekong Delta (VMD). This type of fish is raised with various farming forms (e.g. earthen ponds, netting cages and lined tanks) and at a level of intensive farming [1]. During last decade, from 2006 to 2016, snakehead fish farming increased with 3.4 times of the farming area and 4.6 times of the output, focusing mainly in the upstream and the central area of the VMD such as An Giang, Dong Thap, Hau Giang, Can Tho and Vinh Long. However, consumption market has created a big challenge for snakehead fish farming recently. In order to obtain high yields, farmers have to feed at high dosage/frequency, resulting in a large amount of wastewater and sludge originating from excessive feed and excretions of the fish, posing pollution of farming environment. The toxins generated from the degradation of wastes in fish ponds cause the contaminated environment, lead to the occurrence of various diseases. So then a large amount of aquaculture chemicals is used in the ponds, posing the accumulation of chemicals in aquaculture products and the chemical residuals in the environment.

Results from the authors' survey showed that snakehead fish farming in lined tank was interested by farmers (accounting for $27.7 \%$ of surveyed farms) because it saves the area $\left(37.75 \pm 61.9 \mathrm{~m}^{2}\right)$ and convenient for water quality management [2]. However, most of snakehead fish farming were often spontaneous, small scale and less farming technique, leading to inadequate water management, especially for amount of wastewater generated from the link tanks. Nowadays, the treatment method of wastewater from aquaculture ponds are very popular such as settlement, filtration, etc., but the antibiotic residues and pathogens in water have been not completely removed yet. In addition, the criteria of aquaculture and the ability of farmers in applying water treatment technologies to practical conditions are still very limited. Cold plasma technology is reviewed a highly effective 
technique in treating microorganisms (i.e. coliforms) and organic compounds in wastewater at high voltage [3, 4 , 5] and reducing about $50 \%$ of pesticide fenobucarb concentration in pesticides wastewater [6]. Cold plasma may degrade the residue of antibiotic sulfadiazine used in animal husbandry at a concentration of $10 \mathrm{mg} / \mathrm{L} \mathrm{[7]}$. Coagulation - flocculation process is very effective in removing suspended solids, often followed by the subsequent stages such as sedimentation or filtering process. Researches on the application of these two technologies to treat pesticide wastewater showed a high efficiency, less treatment area, low operating costs and being environmentally friendly as well. By the importance of environmental protection, the necessity of wastewater treatment and investment acceptance of the farmer, an application of the combination of cold plasma and coagulation - flocculation process for treating wastewater from the lined tank of snakehead fish is estimated in this study.

\section{Methodology}

\subsection{Experimental design}

Treatment of wastewater from snakehead fish tanks was performed on a laboratory scale model. The laboratory scale model consisted of two main clusters (1) a coagulation - flocculation tank cluster using poly aluminium chloride (PAC) 10\%, rapid stirring of $200 \mathrm{rpm}$, slow stirring of $100 \mathrm{rpm}$ and $50 \mathrm{rpm}$, settling times at 30 minutes and (2) cold plasma chamber. The designed capacity of the model is $2.88 \mathrm{~m}^{3} / \mathrm{day}$. Water after treated by flocculation and sedimentation was pumped to the plasma chamber at a flow of $2 \mathrm{~L} / \mathrm{min}$. The working mechanism of a cold plasma chamber is modified from [8]: Voltage of plasma generator at $17 \mathrm{kV}$, direct and indirect air flow to plasma of $4 \mathrm{~L} / \mathrm{min}$ and $10 \mathrm{~L} / \mathrm{min}$, respectively. After treated by cold plasma water was collected for checking the quality.

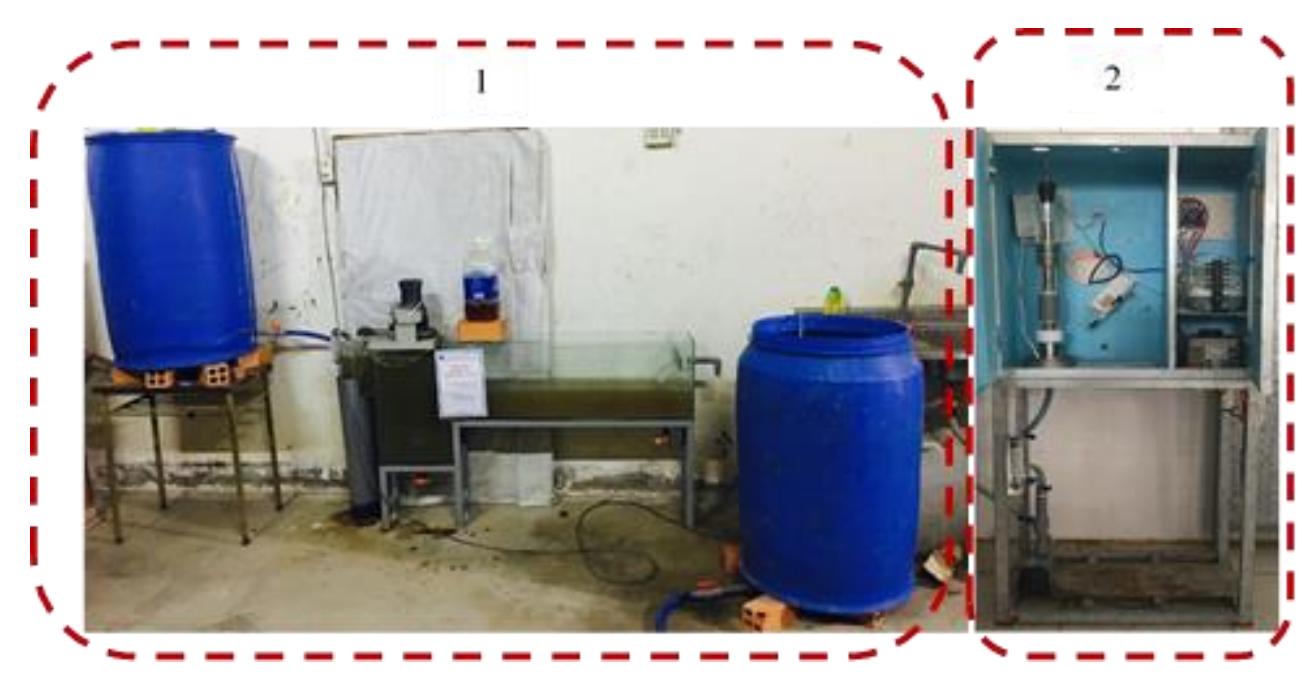

(1) Coagulation - flocculation tank (2) Cold plasma chamber

Fig. 1: Lab-scale treatment model of wastewater from snakehead fish lined tank

\subsection{Water sample analysis and data processing method}

The analytical procedures of basic physio-chemical properties was complied with Vietnamese standard and the Standard Method for the Examination of Water and Wastewater (SMEWW). Particularly, the concentration of antibiotic oxytetracyline in water was determined by LC-MS equipment with method detection limit of 10 $\mu \mathrm{g} / \mathrm{L}$. Descriptive statistical tool of Microsoft Excel software version 2013 was used to process water quality data. 


\section{Results and discussion}

\subsection{Alum dosage for treatment}

Jar-test experiment was carried out with 6 selected PAC alum dosage: $0 \mathrm{mg} / \mathrm{L}, 50 \mathrm{mg} / \mathrm{L}, 150 \mathrm{mg} / \mathrm{L}, 250$ $\mathrm{mg} / \mathrm{L}, 350 \mathrm{mg} / \mathrm{L}, 450 \mathrm{mg} / \mathrm{L}$. Three stirring speeds were selected consisting of $200 \mathrm{rpm}$ (quick stirring), $100 \mathrm{prm}$ and $50 \mathrm{rpm}$ (slow stirring). Measurement of turbidity from the experiment showed that PAC dosage of $250 \mathrm{mg} / \mathrm{L}$ was the most suitable for the treatment process. Wastewater treatment on a lab-scale was performed with three replications.

\subsection{Flow rate and the number of water circulation times in the plasma column}

Nine different treatments were tested with the flow and the number of water circulation corresponding to 1.5 $+1(1.5 \mathrm{~L} / \mathrm{min}$ flow + Number of circulation 1 time $) ; 1.5+2 ; 1.5+3 ; 2+1 ; 2+2 ; 2+3 ; 2.5+1 ; 2.5+2 ; 2.5+$ 3 , respectively. The treatment selected for official experiment must be corresponding to the lowest concentration for turbidity, EC and COD. Experimental results showed that the treatment with the flow rate of $2 \mathrm{~L} / \mathrm{min}$ and the number of water circulation 1 time, the concentration of turbidity, EC and COD was lowest compared to the remaining treatments. In addition, at one water circulation time, nitrate generated had the lowest concentration in the treatments. Therefore, the flow rate of $2 \mathrm{~L} / \mathrm{min}$ and 1 time of water circulation were selected for the official experiment.

\subsection{Treatment efficiency of wastewater from snakehead fish lined tank}

The average $\mathrm{pH}$ value of the effluent was within the neutral range $(\mathrm{pH}=6.7 \pm 0.3)$. $\mathrm{pH}$ of water after plasma treatment was reduced $(\mathrm{pH}=6.31 \pm 0.27)$ within the allowance range of the Vietnamese technical regulation on industrial wastewater - QCVN 40: 2011/BTNMT (column A). Due to the plasma forming process, nitrogen gas in the air supplied into the model is oxidized to $\mathrm{NO}_{\mathrm{x}}, \mathrm{HNO}_{2}$ and $\mathrm{HNO}_{3}[9,10,11]$. The electrical conductivity of wastewater increased during treatment. After coagulation - flocculation and cold plasma phase, EC increased from $592 \pm 42 \mu \mathrm{S} / \mathrm{cm}$ to $686 \pm 79 \mu \mathrm{S} / \mathrm{cm}$. This increase was partly due to the effect of PAC alum dissociation producing free ions in water such as $\mathrm{H}^{+}, \mathrm{Cl}^{-}, \mathrm{Al}^{3+}$ in the coagulation- flocculation process, together with ions produced from the activity of plasma $[3,4,5,11]$.

The turbidity value of the effluent was high $(164 \pm 19$ NTU). The experiment results showed that the turbidity of water after treated sharply reduced to $10.8 \pm 11 \mathrm{NTU}$, with treatment efficiency of $93.4 \%$. Turbidity treatment efficiency was only high in the coagulation - flocculation phase, cold plasma phase was not significantly affect to turbidity reduction.

Total coliforms in the effluent were quite high $(21000 \mathrm{MPN} / 100 \mathrm{~mL})$. After treatment with coagulation flocculation and cold plasma, total coliforms were reduced to $860 \pm 33 \mathrm{MPN} / 100 \mathrm{~mL}$. Treatment efficiency reached 96\% and met the allowance regulation value of column A (QCVN 40: 2011/ BTNMT). Coliforms are partially treated at the coagulation - flocculation stage due to the process of bacteria adhering to the settled sewage. In addition, UV and oxidants generated during plasma activity neutralize the DNA of viruses, bacteria and other pathogens. These factors destroy the link between adjacent single nucleic acids in the DNA of the microflora organisms that cause microbial death or cause genetic code disruption in the molecule to prevent the reproduction and translation of the code. These mechanisms of cold plasma technology are highly effective in water disinfection $[11,12]$.

Concentration of suspended solids of the effluent were quite high $(175 \pm 28 \mathrm{mg} / \mathrm{L})$. After treatment the suspended solids concentration reduced to $18.1 \pm 5.02 \mathrm{mg} / \mathrm{L}$. The treatment efficiency of suspended solids reached nearly $90 \%$ and its concentration was lower than the allowable value of column A (QCVN 40:2011/BTNMT). The concentration of suspended solids decreased mainly from the coagulation-flocculation process. Ions generated from the PAC hydrolysis is able to neutralize the colloidal charge, forming $\mathrm{Al}(\mathrm{OH})_{3}$ precipitates to adsorb the colloidal particles and engaging suspended solids in settled sewage [13]. 


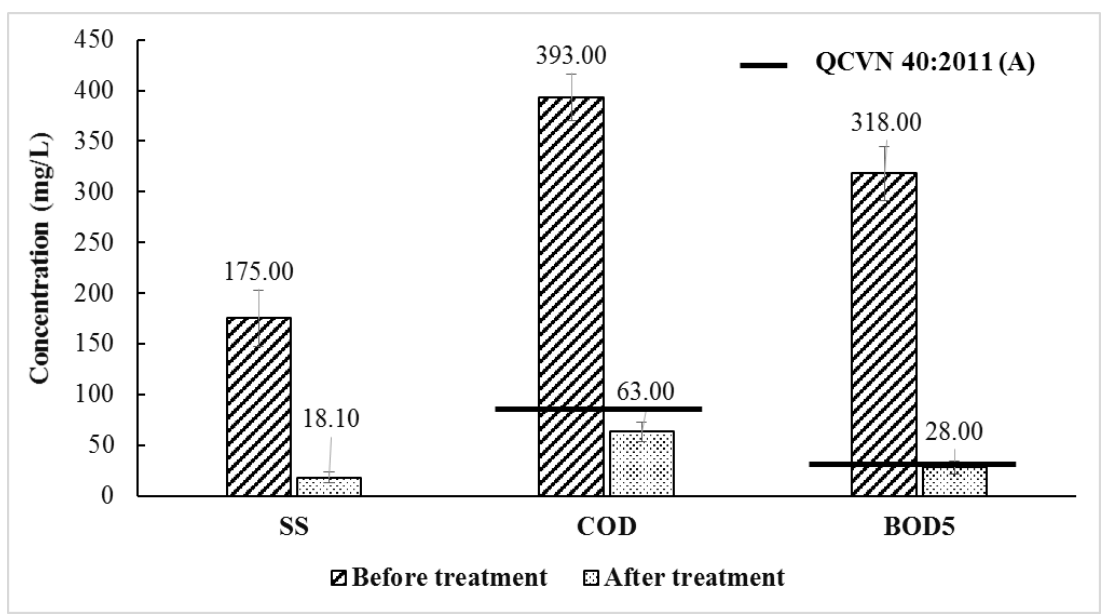

Fig. 2: Concentration of SS, COD and $\mathrm{BOD}_{5}$ before and after treatment

Experimental results showed that the concentration of chemical oxygen demand (COD) decreased from 393 $\pm 23 \mathrm{mg} / \mathrm{L}$ to $63 \pm 9.5 \mathrm{mg} / \mathrm{L}$ (Fig. 2). The output concentration of COD was lower than the allowable regulation value of column A (QCVN 40:2011/BTNMT), achieving a treatment efficiency of 84\%. Organic matters in wastewater are in the form of suspended solid and colloidal particles. When the concentration of suspended solid decreases, the concentration of chemical oxygen demand could be also reduced accordingly. Together with oxidation, conversion of organic matters in wastewater by agents such as ozone, $\mathrm{H}_{2} \mathrm{O}_{2},{ }^{*} \mathrm{OH}, \mathrm{O}^{*}, \mathrm{H}^{*}, \mathrm{O}^{2-*}, \mathrm{HO}_{2}{ }^{*}$, shock waves, electric fields and UV rays generated in the active stage of plasma reduces the content of organic matters in the water, leading to a decrease of COD value [14]. However, the COD treatment efficiency at this stage was low because the number of oxidizing agents produced was less, not enough to completely oxidize organic substances. The composition of wastewater from snakehead fish tank is mainly biodegradable organic substances, so the coagulation - flocculation process is high potential to remove these components. Concentration of biological oxygen demand $\left(\mathrm{BOD}_{5}\right)$ in the output decreased to $28 \pm 6.5 \mathrm{mg} / \mathrm{L}$. It is lower than the allowable regulation value of column A (QCVN 40:2011/BTNMT), corresponding to the treatment efficiency of $91 \%$.

The phosphorus concentration of the effluent was low, so the removal of this component from wastewater was through the mechanism of coagulation - flocculation. Study results showed that total phosphorus concentration decreased sharply from $8.8 \pm 1.2 \mathrm{mg} / \mathrm{L}$ to $0.6 \pm 0.15 \mathrm{mg} / \mathrm{L}$. Cold plasma stage following that was not able to reduce phosphorus. Reduction of phosphorus is explained that the PAC alum reacts with ortho- and poly-phosphorus in the wastewater to form a precipitate $\mathrm{AlPO}_{4}$ and settle into sludge. This mechanism reduces the concentration of total phosphorus (TP) in the wastewater according to the following reaction:

$$
\mathrm{Al}^{3+}+\mathrm{H}_{\mathrm{n}} \mathrm{PO}_{4}^{-(3-\mathrm{n})} \Leftrightarrow \mathrm{AlPO}_{4}+\mathrm{nH}^{+}
$$

Concentration of nitrite and nitrate was not detected in the effluent, but nitrite was detected in water after treated by cold plasma at a low concentration of $0.28 \mathrm{mg} / \mathrm{L}$. The operation of cold plasma could create unwanted products such as nitrite and nitrate as revealing in previous studies [3, 4, 5, 11]. Parameter Total Kjeldahl nitrogen (TKN) was effectively controlled by the coagulation - flocculation process. Concentration of TKN reduced from $11.1 \pm 2.3 \mathrm{mg} / \mathrm{L}$ to $7.27 \pm 1.34 \mathrm{mg} / \mathrm{L}$ after passing through this stage. Cold plasma process was less effective in reducing the concentration of this parameter, only 3\% approximately. The organic nitrogen absorbed into the colloidal particles to make TKN concentration falling after treatment. In addition, a small fraction of organic nitrogen is oxidized and decomposed into inorganic substances under the plasma condition. 


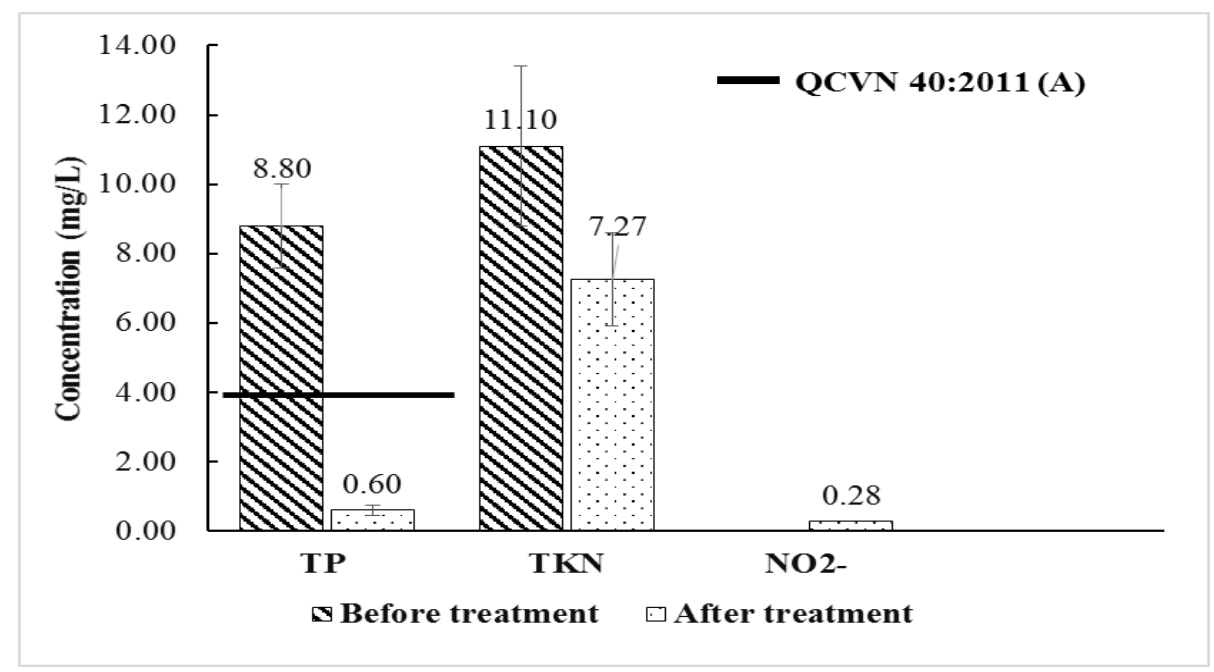

Fig. 3: Concentration of TP, TKN and $\mathrm{NO}_{2}{ }^{-}$before and after treatment

Interestingly, an antibiotic oxytetracycline was considered to evaluate its removal efficiency by the wastewater treatment model. This antibiotic was commonly used to treat diseases in snakehead fish lined tank and it was also a potential pollutant as entering into the water environment. According to the results of household interview of the authors and in a survey of Dang et al. [15], there were many antibiotics used in the Vietnamese Mekong Delta, of which oxytetracyline was commonly used in freshwater aquaculture. But, according to the results of testing the water quality in the target snakehead fish lined tank, this antibiotic was not detected in the effluent. Therefore, the experiment of removing this antibiotic from wastewater was performed by spiking a commercial chemical product, trade named OTC 5000 (oxytetracyline concentration of $500 \mathrm{mg} / \mathrm{g}$ ), in wastewater to get a calculated residue concentration of oxytetracycline was $10 \mathrm{mg} / \mathrm{L}$ approximately. Oxytetracycline residue in the input wastewater was determined with concentration of $11.18 \pm 0.89 \mathrm{mg} / \mathrm{L}$.

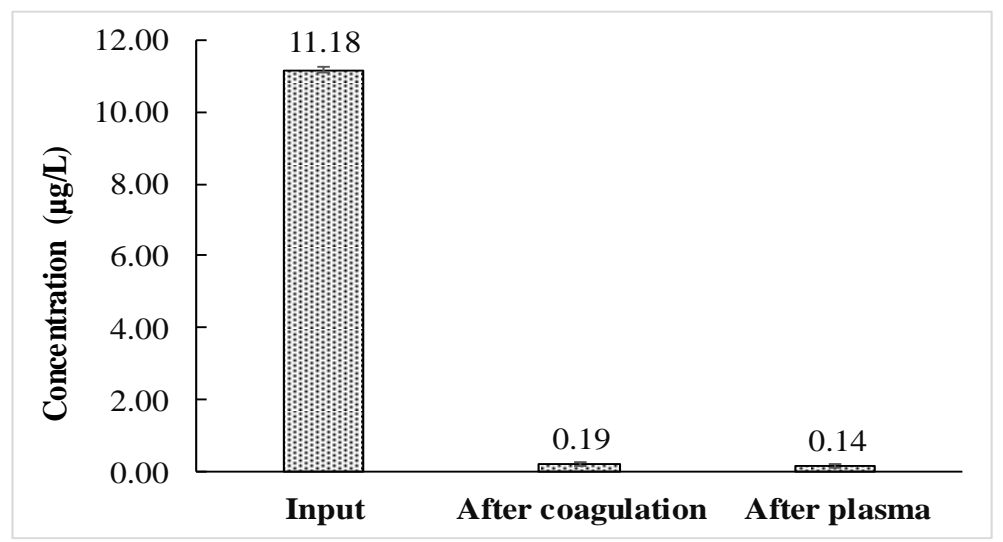

Fig. 4: Concentration of oxytetracycline each stage of treatment

As shown in Fig. 4 after passing the coagulation - flocculation stage the concentration of oxytetracycline was decreased to $0.19 \pm 0.05 \mathrm{mg} / \mathrm{L}$. It revealed that the efficiency of coagulation - flocculation method in removing this antibiotic from water is very high $(98.3 \%)$. The organic carbon-water partition coefficient $\left(\mathrm{K}_{\mathrm{oc}}\right)$ of oxytetracycline ranges from 27.792 to $93.317 \mathrm{~mL} / \mathrm{g}$, so this substance is easily absorbed by suspended solids. When the suspended solids decreased sharply in the coagulation - flocculation stage, the concentration of oxytetracycline was also reduced. The concentration of oxytetracycline was less decreased in cold plasma phase, 
from $0.19 \pm 0.05 \mathrm{mg} / \mathrm{L}$ to $0.14 \pm 0.05 \mathrm{mg} / \mathrm{L}$. Cold plasma was less efficient in removing oxytetracyline from water in this study. It could be that circulation time of water passing plasma column and voltage of plasma chamber were insufficient to the substance degraded by oxidants from cold plasma. Although this technology is revealed that it can degrade well the residue of antibiotic sulfadiazine in animal husbandry [7].

\section{Conclusion}

The system combining the coagulation - flocculation and cold plasma technologies was high effective in treating snakehead tank wastewater. Wastewater after treated by the system reached the water quality standards and can be discharged into receiving water body. However, the treatment efficiency, especially for antibiotic, was only high in the coagulation - flocculation stage. The formation of oxidizing agents in cold plasma chamber was insufficient to degrade pollutants. Further research on improving voltage of the plasma chamber to enhance the wastewater treatment efficiency of the whole system.

\section{Acknowledgement}

This study is funded in part by the Can Tho University Improvement Project VN14-P6, supported by a Japanese ODA loan. The authors would like to express sincere thanks to the enthusiastic support of the members during the project.

\section{References}

[1] L. X. Sinh and D. M. Chung, "Survey of the farming of snakehead fish (Channa micropeltes and Channa striatus) in the Mekong Delta," The journal of Agriculture and Development - Nong Lam University, 2010, pp. 436 - 447.

[2] P. V. Toan, M. P. Vinh, N. T. Hieu, "The real situation of Snakehead fish culture and water quality in lined tank for fish culture in the Mekong Delta of Viet Nam," Special issue: Enviromental Science, Journal of Vietnamese Environment, 2019, pp. 37 - 43.

[3] B. Jiang, I. Zheng, X. Lu, Q. Liu, M. Wu, Z. Yan, S. Qiu, Q. Xue, Z. Wei, H. Xiao, M. Liu, "Degradation of organic dye by pulsed discharge non-thermal plasma technology assisted with modified activated carbon fibers," Chemical engineering journal, 2013, 215-216, pp. 969 - 978.

https://doi.org/10.1016/j.cej.2012.11.046

[4] G. Hey, "Application of chemical oxidation processes for the removal of pharmaceuticals in biologically treated wastewater," Doctoral thesis, Faculty of Engineering of Lund University, Sweden, 21 February 2013.

[5] M.Tichonovas, E. Krugly, V. Racys, R. Hippler, V. Kauneliene, I. Stasiulaitiene, D. Martuzevicius, "Degradation of various textile dyes as wastewater pollutants under dieletric barrier discharge plasma treatment," Chemical Engineering Journal, 229, 2013, pp. 9-19.

https://doi.org/10.1016/j.cej.2013.05.095

[6] N.V. Dung, M.P. Vinh, N.T. Loan, P.V. Toan, “A study of cold plasma for water treatment," Da Nang University Journal of Science and Technology, 1, 2017, 110.

[7] S.P. Rong, Y.B. Sun and Z.H. Zhao, "Degradation of sulfadiazine antibiotics by water falling film dielectric barrier discharge," Chinese Chemical Letter, 25, 2014, pp. 187-192.

https://doi.org/10.1016/j.cclet.2013.11.003

[8] N. V. Dung and N. H. Hanh, "A study on breakdown characteristics of the cold plasma chamber," Can Tho University Journal of Science, 35, 2014, pp. 9-16.

[9] B. P. Dojcinovic, G. M. Roglic, B. M. Obradovic, M. M. Kuraica, M. M. Kostic, J. Nesic, D. D. Manojlovic, "Decolorization of reactive textile dyes using water falling film dielectric barrier discharge," Journal off Hazrdous Material, 192, 2011, pp. 763-771.

https://doi.org/10.1016/j.jhazmat.2011.05.086 
[10] P. M. K. Reddy, "Degration of aqueous organic pollutants by catalytic nonthermal plasma based advanced oxidation process," Doctoral thesis, Department of Chemistry, Indian institute of Technology Hyderabad. 2014.

[11] N. V. Dung, H. Q. Phong, P. V. Toan, N. V. Tuyen, K. Lavane, “A study on treatment of surface water using cold plasma for domestic water supply," Environmental Engineering Research, 2019, pp. 1-17.

[12] J.W. Lackmann, S. Schneider, E. Edengeiser, F. Jarzina, S. Brinckmann, E. Steinborn, M. Havenith, J. Benedikt, J. E. Bandow, "Photons and particles emitted from cold atmosphericpressure plasma inactivate bacteria and biomolecules independently and synergistically," Journal of the Royal Society Interface, 10, 2013, pp. 1-12.

https://doi.org/10.1098/rsif.2013.0591

[13] B.T. T. Loan, "Nghiên cứu phương pháp xử lý nước thải công nghiệp in," Vietnamese, Doctor thesis, Hanoi University of Science and Technology, Vietnam, 2012.

[14] M. H. Valsero, R. Molina, A. Montras, M. Muller, J. M. Bayona, "Decontamination of waterborne chemical pollutantss by using atmosperic pressure nonthermal plasma: a review," Journal on Environmental Technology Reviews, 3:1, 2014, pp. 71-91.

https://doi.org/10.1080/21622515.2014.990935

[15] P. K. Dang, C. Jacqueline, D. T. Nga, B. Francois, D.Guy, D. Philippe, D. P. Edwin, D. Caroline, N. V. Kinh, V. D. Ton, S. L. Marie, W. F. L. Heiman, "Monitoring Antibiotic Use and Residue in Freshwater Aquaculture for Domestic Use in Vietnam," EcoHealth, 12, 2015, pp. 480-489.

https://doi.org/10.1007/s10393-014-1006-z 